\title{
The Research on Order Parameter of E-commerce Industry System Based on The Theory of Coordination
}

\author{
Liping Zhang ${ }^{1, a,{ }^{*}}$, Xiaodong $\mathrm{LI}^{2, \mathrm{~b}}$ \\ ${ }^{1}$ School of Logistics, Lin Yi University, Shandong 276000, China \\ ${ }^{2}$ School of Logistics, Li Yi University, Shandong 276000, China \\ a1692964355@qq.com, b15653976597@163.com
}

\begin{abstract}
As leading industry, e-commerce industry becomes more important to the market operation of our country economy development. At the same time by the scientific community attaches great importance to the system of e-commerce industry. But the research of e-commerce industry also stays on qualitative analysis, the research on the evolution development of e-commerce industry system is less. In this paper, on the basis of the theory of co-evolution, the synergy evolution equation on the system is built. through the empirical analysis we study order parameter on the evolution development of e-commerce industry system. it's provided reference for the rapid development of e-commerce industry.
\end{abstract}

Keywords: e-commerce industry system, synergistic effect, order parameter.

\section{Introduction}

A few days ago, following the development and improvement of the Internet infrastructure, E-commerce of China has maintained a high rate of growth, which mainly reflected in rising on the volume of trade, the amount of online people and the number of e-commerce sites. All kinds of shops, such as clothing, goods, electrical appliances and plates, are also registered and applied e-commerce platform. As the number of e-commerce enterprises on the market gradually increased, the e-commerce industry is becoming more and more mature. More and more enterprises and individuals participate in in the e-commerce industry, formed a mature system of e-commerce industry. As a new industrial system, the system of electronic commerce has a great influence on the development of national economy. The development process about the system of the electronic commerce industry is the focus in the present research, and it has a far-reaching impact on its quantitative analysis. The main significance of this research is in the following two aspects. On the one hand, the e-business system is defined by the study of electronic business system, and the concept model of electronic business system is put forward. On the other hand, based on the theory of Coordination, analysis the evolution of e-commerce industry system, determine the dominant factor. To certain empirical study of e-commerce industry provide theoretical reference for the coordinated development of e-commerce industry.

\section{The Connontation and Structure of The System of Electronic Commerce Industry}

\subsection{The Conceptual Model of The System about Electronic Business}

Individuals, enterprises and organizations, which provide goods and services for specific end users, form an whole organic in the environment of electronic commerce. the whole organic dominated by e-commerce, and all kinds of organizations join this system of e-commerce enterprises, such as government organizations, manufacturers, trade companies, information software enterprises, logistics companies, financial companies and so on. It also brings in a large number of value-added services that provide by training institutions about education, certification and so on. These organizations provide corresponding services for e-commerce companies, developing together with e-commerce companies and forming the system of electronic commerce. It is obvious that the e-commerce model has penetrated the traditional manufacturing increasingly. Many of the traditional 
manufacturing industries relying on e-commerce, has been upgraded to modern manufacturing industries, through extending the value chain of upstream and downstream. To sum up, through the Internet as a means of communication, companies and organizations closely relationships connect together to form a self-organizing system which share complementary resources, that just is the system of e-commerce. In this system, the members are independent of each other and influence with each other, at the same time, energy inside of the system exchange with energy outside of the system, then this communication form a complex network, the material energy and information circulation flowing in the network.

Firstly In the evolution of system, electronic business enterprise as the core enterprise which provides platform internet lead other companies form e-commerce industry system by integrating resources, as well as coordinate other members by the means of supervising and managing users in the system. Secondly is the Internet platform of e-commerce transactions, trading company design noodles wide, including suppliers, producers, retail and consumer groups, e-commerce enterprises to attract these common push through a deal for the goods and services, etc. As long as it is commodity , it is inseparable from the logistics. In the e-commerce industry system, there are organizations and institutions such as logistics enterprises, telecommunication services, financial institutions. E-commerce relies on these industries for survival and development, while these organizations also benefit from the relevant e-commerce industry. In addition, it deals with providers of value-added service such as consultants, marketing service providers, and technology outsourcing companies in the e-commerce network. The following diagram shows the composition of the e-commerce industry.

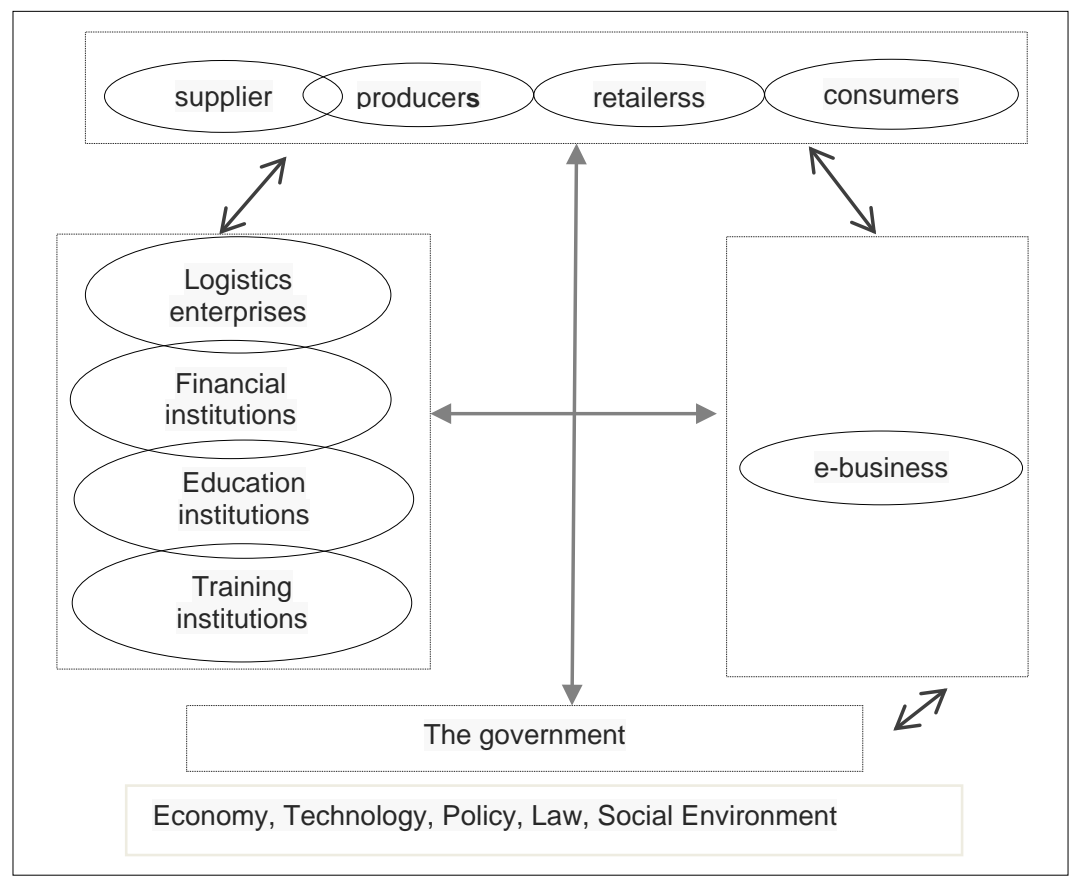

Fig. 1 Conceptual model of electronic business system

\subsection{The Main Body in The System of The Electronic Commerce Industry}

By analyzing the concept of e-commerce industry system and building the concept model of e-commerce industry system, it is clear that the main body of the system can be classified into four categories.

2.2.1E-commerce leaders

The e-commerce leader is the core body of the industrial system, and he has established a third-party e-commerce platform to provide supervision and other services to other partners. Some e-commerce companies are also counterparties, which build e-commerce platforms for various kinds of e-commerce activities. 


\subsubsection{E-commerce traders}

The e-commerce trader is the main economic body in the system, including the seller's enterprise and the buyer's enterprise. They can coordinate production, information exchange and online transactions through e-commerce platforms established by e-commerce companies. It mainly includes suppliers, manufacturers, distributors, retailers and consumers.

\subsubsection{E-commerce services}

E-commerce service providers provide logistics services for e-commerce industry, technical services, personnel training, investment and financing business, the legal consultation and other services. There are mainly logistics enterprises, IT enterprises and financial institutions, education and training Institutions, legal institutions, etc. E-commerce service provider provides each factors for decision and support factors of industrial development, which affects the business efficiency and technical level.

\subsubsection{The government}

The government as guide and regulators of the e-commerce industry, play a very important role for the evolution and development of the e-commerce industry system. Government provides the enterprises with the perfect infrastructure and financial support, at the same time providing institutional mechanisms for the financial security of internet, e-commerce taxation, supervision of platform, such as the provision mechanism, through the industrial and commercial tax departments for industrial policy system to provide the service.

\section{The Analysis of Collaborative and Evolutionary of Electronic Business Systems}

In the collaborative theory, scholars believe that the subsystem of any complex system will approach two directions. One is that the subsystem tends to be disorderly and eventually leads to disorder and disintegration. The other is that subsystems coordinate each other to allow the system to be spontaneously organized. The system is either from disorder to order or from order to disorder depending on which factor plays a major role. So under this dynamic mechanism, each subsystem interacts with each other to allow the system to evolve from low-level to advanced and from disorder to order. The sequence of parameters governs the evolution of the structure, whether it is competition or cooperation. Therefore, it is necessary to study and find the order parameters that govern and dominate the system, and then analyze and predict the direction of the evolution. According to the theory of synergetics in the system of the e-commerce industry, the combination of the overall effect can be divided into complementary effect and synergistic effect, in essence, the complementary effect is the increase of the quantity, and synergistic effect is the improving of quality. it emphasizes the overall efficiency is greater than the individuals of a single function. The evolution of the electronic commerce industry system has been continuously evolving under the dynamics of competition and cooperation of subsystems.

As the division of labor is refined, as a product of traditional business and the Internet technology, e-commerce industry is also a co-evolution, which is new levels of coordination in business system. It is the interaction of competition and synergy that drives the co-evolution of system. Competition forces the whole system to be unbalanced, and the synergy effect is to combine certain trends and amplify the trend. In the continuous game the factors of this tendency gradually take advantage, and become the order parameter, which is the dominant or the servo for the evolution of system. The coevolution of the electronic commerce industry system is embodied in the following two aspects.

\subsection{The Main Body Together}

For business market, the main body of the e-commerce industry leaders including e-commerce, e-commerce traders, e-commerce service providers, and government, and between them there is a mutual relationship of cooperation and competition with each other.From the perspective of supply chain development, coordination and cooperation of each subsystem is needed from the perspective of the whole industry system, strengthening the positive interaction. 


\subsection{The Structural Evolution of Economic Space}

According to the spatial configuration of the system, the structure of electronic commerce industry can be divided into the point structure, the chain structure and the network structure. Because of system activity develops in society, economy, culture and environment, it makes the system must carry on the coordination between economic activity, at the same time, due to the need of the development of individual self-interest, there exists a negative interaction of the system activity. The collaborative evolution of e-business systems depends on the interaction and interaction between enterprises and enterprises. The continual evolution of the enterprise has led to the evolution of the system as a whole. In the process, one or several factors which occupy the dominant position and drive the whole development of system affect enterprise development of the individual and the whole evolution of system, and this one or several factors are the order parameters of the system.

\section{The Collaborative Evolution of The E-business System}

\subsection{The Selection of The Measures of Coordination}

The system of the electronic commerce industry mainly consists of e-commerce leaders, e-commerce services, e-commerce traders and government. The system can be divided into four subsystems: leader, service provider, trader and government. In determining the evaluation indicators in these subsystems, we should select them based on the principle of operability and validity. Specific include: (1) Availability of data can be processed and processed in the existing data. (2) The quantifiable nature of data is mainly based on real, reliable and effective quantitative variables, even when qualitative variables are used we should convert them to relevant quantitative variables or as little as possible. (3) It is appropriate to evaluate the number of variables, otherwise too many variables will cause the analysis to be complex and difficult. (4) the evaluation variable system should conform to the evaluation object, and the higher the correlation, the more reasonable the selection of the variable. According to the above principles, the evaluation indexes of each subsystem are determined by the analysis system.

Table 1 Measurement of electronic commerce industry system

\begin{tabular}{|c|l|}
\hline The variable name & \multicolumn{1}{c|}{ measurement index } \\
\hline \multirow{2}{*}{$\begin{array}{c}\text { E-commerce } \\
\text { leaders }\end{array}$} & The scale of e-commerce companies $\left(\mathrm{X}_{1}\right)$ \\
\cline { 2 - 2 } E-commerce traders & Comprehensive quality of e-commerce enterprises $\left(\mathrm{X}_{2}\right)$ \\
\hline \multirow{4}{*}{$\begin{array}{c}\text { E-commerce } \\
\text { services }\end{array}$} & The quantity of commercial enterprise $\left(\mathrm{X}_{3}\right)$ \\
\cline { 2 - 2 } & The rate of occupancy of commercial enterprises $\left(\mathrm{X}_{4}\right)$ \\
\cline { 2 - 2 } & The quantity of logistics enterprise $\left(\mathrm{X}_{5}\right)$ \\
\cline { 2 - 2 } & The development of consultancy services $\left(\mathrm{X}_{7}\right)$ \\
\cline { 2 - 2 } & The ability of the transformation of scientific and technological achievements $\left(\mathrm{X}_{8}\right)$ \\
\hline \multirow{2}{*}{ The government } & Financial support $\left(\mathrm{X}_{9}\right)$ \\
\cline { 2 - 2 } & Quality and efficiency of administration $\left(\mathrm{X}_{10}\right)$ \\
\hline
\end{tabular}

\subsection{The Establishment of Mathematical Models}

The system of electronic commerce industry is a self-organizing system that is in exchange with the outside world for information, energy, etc. The synergies between the various subjects in the self-organizing system determine the evolution path of system, making the system from disorderly to orderly and then to a higher level of the chaotic dynamic evolution. The thing that drives the evolution of the system is the order parameter of the system. It is very important for the development of the research system to understand the order parameter of the system. Combining with the relevant theory of synergy theory and grey system modeling, mathematical model about co-evolution of e-commerce industry system is established, to determine the system synergy evolution of order parameter. 
Let $X_{1}(t), X_{2}(t), \cdots, X_{n}(t)$ for the variable value in the period t, Wherein, Namely total number of values has $m$ group. The main system is mainly due to an internal order parameter, thus not consider the fluctuating force. The following is a detailed analysis of the process:

(a)The dimensionless variables of postscript to $X_{i}^{0}(t)$,inside, $\mathrm{i}=1,2, \ldots \mathrm{n}$;

(b)Make the number of columns $X_{i}^{0}(t)$ as cumulative process, and generate new variable series Denoted as $X_{i}^{1}(t)$,inside, $\mathrm{i}=1,2, \ldots \mathrm{n}$;

(c)The rate of change of the number of columns $X_{i}^{1}(t)$ is recorded as $d X_{i}^{1}(t) / d t$, According to the system theory, Internal systems and external synergies will affect the rate of change. Wherein internal synergies role in promoting the development of each variable is $p_{i i} X_{i}^{1}(t)$, The role of external synergies denoted as $p_{i j} X_{i}^{1}(t)$. Restricting the development of each variable internal synergies role is $-q_{i i}\left(X_{i}^{1}(t)\right)^{2}$. External synergies denoted $-q_{i j}\left(X_{i}^{1}(t)\right)^{2}$. Thereby obtaining the following formula to indicate the rate of change $d X_{i}^{1}(t) / d t$.

$$
\begin{array}{r}
\frac{d X_{i}^{1}(t)}{d t}=\sum_{j=1}^{m} p_{i j} X_{j}^{1}(t)-\sum_{j=1}^{m} q_{i j}\left(X_{j}^{1}(t)\right)^{2} \\
\text { Wherein } i, j=1,2, \cdots n
\end{array}
$$

Using Matlab software to solve the above model. First of all by the $\frac{d X_{i}^{1}(t)}{d t}=X_{i}^{1}(t)-X_{i}^{1}(t-1)=X_{i}^{0}(t)$ obtained $X_{i}^{0}(t)=\sum_{j=1}^{m} p_{i j} X_{j}^{1}(t)-\sum_{j=1}^{m} q_{i j}\left(X_{j}^{1}(t)\right)^{2}$ following equations(3).

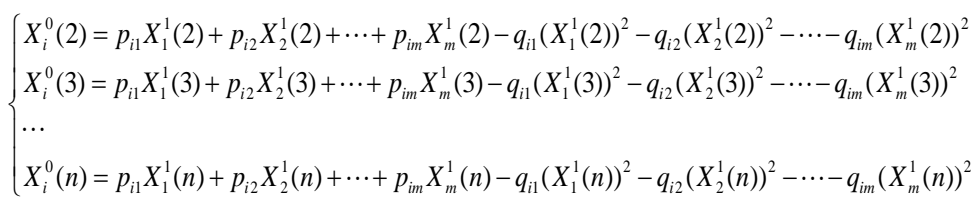

Equation (3) can be obtained after sorting $y_{i}=A_{i} * B_{i}$, among them,

$$
\begin{aligned}
y_{i}=\left[\begin{array}{l}
X_{i}^{0}(2) \\
X_{i}^{0}(3) \\
\cdots \\
X_{i}^{0}(n)
\end{array}\right] \\
A_{i}=\left[\begin{array}{lllll}
X_{1}^{1}(2) & X_{2}^{1}(2) \cdots & X_{m}^{1}(2)-\left(X_{1}^{1}(2)\right)^{2}-\left(X_{2}^{1}(2)\right)^{2} \cdots-\left(X_{m}^{1}(2)\right)^{2} \\
X_{1}^{1}(3) & X_{2}^{1}(3) \cdots & X_{m}^{1}(3)-\left(X_{1}^{1}(3)\right)^{2} & -\left(X_{2}^{1}(3)\right)^{2} \cdots-\left(X_{m}^{1}(3)\right)^{2} \\
\cdots & & & \\
X_{1}^{1}(n) & X_{2}^{1}(n) \cdots & X_{m}^{1}(n)-\left(X_{1}^{1}(n)\right)^{2}-\left(X_{2}^{1}(n)\right)^{2} \cdots-\left(X_{m}^{1}(n)\right)^{2}
\end{array}\right] \\
B_{i}=\left[\begin{array}{lllllll}
p_{i 1} & p_{i 2} \cdots & p_{i m} & q_{i 1} & q_{i 2} \cdots & q_{i m}
\end{array}\right]^{T}
\end{aligned}
$$

Specific values can be obtained according to , At the same time According to the model obtained Relaxation coefficient of each variable p_ii, inside $i=1,2, \ldots n$. According to the value of the relaxation factor can determine Variables can be regarded as the order parameter. 


\section{Conclusions}

To study the development of e-commerce industry in China, we need to use quantitative methods to analyze. Through the study, the system of electronic commerce industry is an open self-organizing system which has unlimited development space. Systematic collaboration is necessary for the development of the industry. Depending on the different system of electronic business, the system structure and the state order parameter are different. As an emerging industry, e-commerce industry faces a higher risk of recession and death, while the policy environment and information technology of the industry are highly variable. There will be varying degrees of change and renewal of the e-business system from birth to maturity. Based on the theory of synergy, this paper discusses the system of electronic commerce industry theoretically. From the analysis of electronic commerce subject and economic space configuration, the development of e-commerce industry has strong guidance and reference significance. This paper selects the research indicators and then uses the co-evolutionary mathematical model to determine the numerical method of the order parameter.

\section{References}

[1] Zhao zhitian, Yang jianzheng. Research onThe Development of Cross-border E-commerce in China under The Theory of Industrial Innovation System[J]. Development of China, ,2014,02:25-30. [2] Zheng Runping. The Study of The Electronic BusinessEcosystem and Its Evolutionary Path[J]. The knowledge Economy,2015,23:79-81.

[3] ZhanJinyong, Xu Zongli. The Internal Evolution Mechanism of Ecosystem of China's E-commerce is Explored--in The Case of The Ecosystem of Alibaba[J]. The Chinese and Foreign Entrepreneurs,2015,25:241.

[4] Zhong Yan Lin. Research on the Optimization Path of Regional Tertiary Industry from E-Commerce Perspective - In the Case of Fujian Province[J]. Advanced Materials Research,2013,2586(774):.

[5] Yu Ling Liu. Research on the New Trend in E-Commerce Industry: Mobile E-Commerce[J]. Advanced Materials Research,2014,3181(926):.

[6] Rama Prasad Kanungo. E-commerce in the pharmaceutical industry: threshold of innovation[J]. Management Research News,2004,27(8):. 